Rabaska

Revue d'ethnologie de l'Amérique française

\title{
La Chaire de recherche du Canada en patrimoine urbain
}

\section{Luc Noppen}

Volume 6, 2008

URI : https://id.erudit.org/iderudit/000178ar

DOI : https://doi.org/10.7202/000178ar

Aller au sommaire du numéro

Éditeur(s)

Société québécoise d'ethnologie

ISSN

1703-7433 (imprimé)

1916-7350 (numérique)

Découvrir la revue

Citer ce document

Noppen, L. (2008). La Chaire de recherche du Canada en patrimoine urbain. Rabaska, 6, 258-260. https://doi.org/10.7202/000178ar d'utilisation que vous pouvez consulter en ligne.

https://apropos.erudit.org/fr/usagers/politique-dutilisation/ 


\section{La Chaire de recherche du Canada en patrimoine urbain}

Institut du patrimoine, DC-1200 Téléphone : (514) 987-3000, poste 2562

Université du Québec à Montréal

C.P. 8888 , Succursale Centre-Ville

Montréal (Québec) H3C 3P8
Télécopieur : (514) 987-6881

Courriel : noppen.luc@uqam.ca

Toile : www.patrimoine.uqam

\section{Présentation}

Cette Chaire a été créée en juin 2001 à l'Université du Québec à Montréal, où elle a été logée à l'École des sciences de la gestion (ESG) et son titulaire rattaché au Département d'études urbaines et touristiques de cette faculté. L'UQÀM m'a recruté à l'Université Laval, où j'enseignais au Département d'histoire et à l'École d'architecture, et menais des recherches depuis 1972 en histoire de l'architecture et en patrimoine. Comme titulaire de la nouvelle CRC en patrimoine urbain, j'ai œuvré à la mise sur pied de l'Institut du patrimoine de l'UQÀM dont j'ai été nommé premier directeur en 2005 (www.ip.uqam.ca). Ce premier mandat vient d'être renouvelé pour un second terme (2008-2011).

La Chaire a produit un premier rapport d'activités (2001-2008) disponible sur le site www.patrimoine.uqam - et soumis un projet de renouvellement soutenu par l'UQÀm et accepté par le Bureau des Chaires de recherche du Canada. La CRC en patrimoine urbain - EsG a donc été reconduite pour un deuxième mandat de sept ans (2008-2015), en date du premier juin dernier. Ce renouvellement coïncida avec l'octroi d'une subvention de quelque 2 millions \$ (Luc Noppen, Lucie K. Morisset) au Forum canadien de recherche publique sur le patrimoine (FCRPP), projet soumis au programme des Réseaux stratégiques de connaissances du CRSH (2008-2015) et d'une subvention ordinaire du CRSH (2008-2011) pour un programme de recherche sur les églises de Montréal, du Québec et du Canada français.

Le programme de recherche originel de la CRC a été mis à jour et développé. Il vise, d'une part, à comprendre structurellement et historiquement la patrimonialisation (l'ensemble des processus et des mécanismes concourant à la fabrication du patrimoine et à son imbrication dans l'identité collective), d'autre part à renouveler des théories et des pratiques de la patrimonialisation, à l'échelle occidentale.

Dans le contexte de la multiplication des patrimoines et de l'expansion exponentielle des champs patrimoniaux, de la mitoyenneté multiculturelle induite par l'accroissement de la mobilité et des échanges et, enfin, dans celui de la confrontation entre l'affection des citoyens pour un patrimoine de proximité et la dévolution des décisions politiques à des acteurs de la scène mondiale, il s'agit, en somme, de contribuer scientifiquement et concrètement 
à une appropriation nouvelle de la formation des identités collectives, en ressaisissant le patrimoine comme projet de société, en fonction des enjeux et des aspirations des populations urbaines de ce siècle. En explorant de manière fondamentale et contextualisée la caractérisation, la conservation et la valorisation du paysage construit, particulièrement dans les villes, cela sera possible grâce aux potentialités du Canada d'être un laboratoire de choix et un cas d'école pour de telles études, autant en matière de recherche fondamentale, compte tenu des collectivités et des cadres bâtis canadiens, qu'eu égard à la recherche-action qui y est favorisée, particulièrement à partir de l’Université du Québec à Montréal.

\section{Résultats de l'année}

Pour 2007-2008, il vaut la peine de signaler quelques réalisations de la CRC en patrimoine urbain. D'abord, le $1^{\text {er }}$ juin 2007, nous avons tenu à SaintJacques de Montcalm (Lanaudière) le Premier Séminaire régional sur l'avenir des églises qui connut un franc succès : une centaine de participants y ont œuvré à des solutions au problème de la désaffectation des églises au Québec. La captation des présentations par la TÉLUQ - la Téléuniversité de l'UQÀM a permis la production de dix émissions d'une demi-heure sur l'Avenir des églises du Québec, qui sont diffusées au Canal Savoir depuis janvier 2008. Le second Séminaire s'est tenu le 3 juillet dernier à l'UQÀM en partenariat avec la Chaire Fernand-Dumont pour la culture (InRs-Société et Culture). Il avait pour thème « Clefs de lecture pour le patrimoine religieux » et donnera lieu à une nouvelle série télévisée sur Canal Savoir.

Le 26 septembre 2007, j'ai, avec ma collègue Lucie K. Morisset, fait une présentation sur la situation du patrimoine architectural ecclésial au colloque Loci Sacri à Leuven, en Belgique (« Heritagization of Church Buildings : Québec and North American Experiences »). En décembre, nous avons tenu à Rennes, avec la collaboration de l'Université de Rennes 2, la Troisième Rencontre internationale des jeunes chercheurs en patrimoine. Quelque vingt participants y ont présenté des communications sur le thème Patrimoines : fabrique, usages et réemplois. La délégation québécoise était composée d'une dizaine de jeunes chercheurs, associés à la CRC ou invités par elle. Cet automne (25-26 septembre 2008), se tiendra à l'UQÀm la Quatrième Rencontre internationale des jeunes chercheurs en patrimoine, en partenariat avec la Chaire Fernand-Dumont pour la culture, sur le thème Patrimoine et sacralisation, patrimonialisation du sacré.

En mars 2008, j'ai été professeur invité à l'École nationale des Chartes (Paris-Sorbonne) où j'ai offert des séminaires sur la patrimonialisation et des conférences sur la question des églises au Québec et en Amérique. 
Enfin, une bonne partie de l'année universitaire 2007-2008 a été consacrée au développement d'un programme de cours sur le patrimoine religieux, qui seront offerts à distance par la TÉLUQ dès l'automne 2009.

LuC NopPen

\section{Société québécoise d'ethnologie}

Centre Alyne-Lebel

310, boul. Langelier, bureau 232

Québec (Québec) G1K 5N3
Téléphone : (418) 524-9090

Courriel : jeansimard@globetrotter.net Toile : www.sqe.qc.ca

Dans le cadre général de sa mission qui est de promouvoir l'ethnologie et de favoriser la sauvegarde et la mise en valeur du patrimoine ethnologique du Québec et des francophones en Amérique du Nord, tant sur le plan immatériel que matériel, la Société québécoise d'ethnologie a mené, depuis son dernier rapport d'activités en 2006, des activités axées principalement sur l'amélioration des connaissances relatives au patrimoine et à leur mise en valeur, et cela avec la collaboration de plusieurs partenaires. À cette fin elle a publié les volumes 4 et 5 de Rabaska, participé aux travaux de l'Inventaire des ressources ethnologiques du patrimoine immatériel (IREPI) et à l'Inventaire du patrimoine religieux immatériel, présenté à la ministre de la Culture, des comunications et de la condition féminine un mémoire sur le projet de refonte de la Loi sur les biens culturels, poursuivi enfin son programme de cinérencontres du patrimoine ethnologique au Musée de la civilisation de Québec.

\section{Mise en valeur des connaissances ethnologiques}

La revue Rabaska, publiée depuis 2003, fait état des activités annuelles dans le champ du patrimoine ethnologique. Elle est distribuée aux membres en règle de la Société (réguliers, corporatifs et étudiants) ainsi qu'à ses collaborateurs. La liste des abonnés compte à ce jour 294 noms de personnes et d'institutions. Nous projetons d'en porter minimalement le nombre à 362 en 2008-2009 du fait de l'inscription de notre revue au portail électronique Érudit qui réunit 68 institutions publiant des revues de langue française en patrimoine et sciences humaines. Rabaska pourra donc bientôt être lue en format électronique par ces 68 nouveaux abonnés, tout comme nos abonnés auront accès gratuitement aux revues publiées par ces 68 institutions.

Le projet IREPI est mis en œuvre par la Chaire de recherche du Canada en patrimoine ethnologique de l'Université Laval dont nous sommes les 